\title{
Research on Evaluation of Collaborative Innovation Ability of Collaborative Innovation Network of Universities Based on Fuzzy Matter Element
}

\author{
Wu Lixiong \\ School of Management \\ Wuhan University of Science and Technology \\ Qingshan district of Wuhan, Hubei in china, 430081 \\ 591134125@qq.com
}

\author{
Li Yongzhou \\ School of Management \\ Wuhan University of Science and Technology \\ Qingshan district of Wuhan, Hubei in china, 430081
}

\begin{abstract}
The aim of this study is to evaluate the collaborative innovation ability of collaborative innovation network of universities. We adopt the theory of collaborative innovation network to clarify the connotation of collaborative innovation ability of collaborative innovation network of universities. And then, construct the evaluation index system of collaborative innovation ability from the input and output, subject coordination and environment construction. With the aim to determine the index weight, we introduced the entropy theory. Finally, 12 collaborative innovation centers in Hubei Province are selected as examples, and the entropy weight fuzzy matter element model and Euclid approach degree are combined to evaluate the collaborative ability. The results suggest that the centers of colleges and universities have higher overall collaborative innovation ability than the others. Our findings indicate that the synergistic innovation ability of university collaborative center needs to be promoted from three aspects: input-output, main subject and environment construction, so as to integrate the multi-resources and realize the maximum output from knowledge to technology and from technology to economy.
\end{abstract}

Keywords-colleges and universities; collaborative innovation network; collaborative innovation ability; evaluation index system; fuzzy matter element

\section{INTRODUCTION}

Since the "2011 plan" that aimed at "building collaborative innovation platform and mode and enhancing the innovation ability of colleges and universities" was implemented in 2012, the university collaborative innovation center has been constructed for five years. The national university collaborative innovation center has deeply integrated the overall strategy of national development, promoted the development of science and technology services in universities, emphasized the innovation of institutional mechanisms, created the collaborative environment, solved key research problems, inherited culture and innovation, solved the key technology problems and serves the regional economy and social development. However, due to the impact of long-term institutional mechanisms, the double-skin phenomena still exists in the science and technology of universities and social development, and many problems for collaborative innovation center, such as decentralized materials, closed and ineffective innovation resources, have not yet been effectively solved.
Compared with Europe and America, there is still a large gap in the collaborative innovation ability and level in China. The enterprises, universities, research institutes and governments never cooperate with each other seemingly in harmony but actually at variance. Therefore, the collaborative innovation has not yet effectively released, the coordination mechanism is not perfect, and the results are distributed unreasonably [1]. Under this context, it is of great theoretical and practical significance to construct a scientific and reasonable evaluation index system of collaborative innovation ability and evaluates it correctly, thus guiding the innovation-driven strategic goal for collaborative innovation subject and activating the collaborative innovation vitality.

\section{THEORETICAL BASIS AND LITERATURE REVIEW}

At the same time, a large number of foreign scholars have studied the collaborative innovation network, and some scholars also begin to focus on collaborative innovation ability evaluation. Barton built the innovative ability evaluation index of core talent, innovation management, technical systems, scientific and technological awareness[2].Simarupang considered the collaborative innovation level from the information sharing, decision-making synchronization, cooperation and incentive [3]; Larry used the organizations and adaptability and technology and information to measure the innovative ability[4]; Barbaroux evaluated the innovative ability from heterogeneous innovation resource selection and connection ability, knowledge management ability, and adaptive management ability[5].After the 1990s, with the further maturity of domestic collaborative innovation network, some scholars have also begun to discuss the collaborative innovation ability from the regional network level. Xie Xuemei established the innovation capacity evaluation system consisting of innovation subject, innovative support and innovation environment from the measurement of regional synergies[6].Ou Guangjun designed the collaborative innovation ability evaluation index system from the innovation cluster system, core support environment and system output effect[7].Kang designed common indicators of synergistic effect between the enterprise and the university and the government, and the interaction index of individual indicators and innovative subjects[8]. Wen Ke considered the 
collaborative innovation capability, alliance capability and organizational design and proposed the collaborative innovation concept of scientific research institutions, so as to realize the development and extension of cooperative network from the regional network[9].On the basis of Wenke's study, Wang Wanjuan studied the key laboratories and believed that the collaborative innovation ability was based on independent innovation, combined the elements of collaborative innovation, integrated the innovative resources to maximize the output and build the relevant index system [10].Fu Yifan [11] and Ding Hong [12] evaluated collaborative innovation ability from the university research team and student work team.

\section{CONSTRUCTION OF EVALUATION INDEX SYSTEM}

At present, there are still fewer studies on collaborative innovation ability evaluation of collaborative innovation network of universities. Only Wang Jiefang and Li Yongzhou evaluated the performance of collaborative innovation center. Wang Jiefang built the evaluation index system from performance structure and evaluation based on innovation, collaboration, and resource sharing and coordination mechanism system[13]. Li Yongjie built the multi-dimensional evaluation index system of collaborative innovation center scale structure, collaborative mechanism, innovative environment and cultural atmosphere[14].According to the mechanism and the inherent requirement of collaborative innovation, the collaborative innovation ability of cooperative innovation network of universities is the collaborative innovation system consisting of enterprise, universities, scientific research institutions, government, financial institutions, science and technology intermediaries and other diversified entities (including personnel, funds, basic platform, laboratory facilities and equipment, etc.), so as to maximize the synergistic effect, and achieve the significant scientific and technological output, high-end talent and huge social benefits. In conclusion, according to the definition of collaborative innovation ability and the organization and research characteristics of collaborative innovation center, combined with its strategic requirements, the organizational objective management and strategic performance are used to divide the evaluation index system into 3 first-level indexes and 25 second--level indexes as Table 1.
TABLE I. EVALUATION INDEX SYSTEM OF COLLABORATIVE INNOVATION ABILITY

\begin{tabular}{|c|c|}
\hline First-level index & Second-level index \\
\hline \multirow{11}{*}{$\begin{array}{c}\text { Collaborative } \\
\text { innovation input } \\
\text { Output capacity } \\
\text { (W1) }\end{array}$} & C1 Research funding investment \\
\hline & C2 Research personnel investment \\
\hline & $\begin{array}{l}\text { C3 Scientific research facilities and equipment } \\
\text { investment }\end{array}$ \\
\hline & C4 Number of paper and works published \\
\hline & $\begin{array}{l}\text { C5Provincial and ministerial scientific achievements } \\
\text { awards }\end{array}$ \\
\hline & C6 Patents, copyrights and software products \\
\hline & C7 Solve the industry and key technical problems \\
\hline & $\begin{array}{l}\text { C8 Provide decision support for major local } \\
\text { government projects }\end{array}$ \\
\hline & C9 Provincial and ministerial technology platform \\
\hline & C10 Talent introduction and training quantity \\
\hline & C11 Economic value created directly or indirectly \\
\hline \multirow{7}{*}{$\begin{array}{c}\text { Collaborative } \\
\text { innovation subject } \\
\text { coordinative ability } \\
\text { (W2) }\end{array}$} & $\begin{array}{l}\text { C12Participation and input of collaborative } \\
\text { innovation subject }\end{array}$ \\
\hline & C13 Academic conference of innovation subject \\
\hline & C14Collaborativeinnovation platform construction \\
\hline & C15 Openness of platform for innovation subject \\
\hline & C16 Laboratory equipment sharing rate \\
\hline & $\begin{array}{l}\text { C17 Interest distribution and resource sharing of } \\
\text { innovation subject }\end{array}$ \\
\hline & $\begin{array}{l}\text { C18 Innovation risk sharing and prevention } \\
\text { mechanism }\end{array}$ \\
\hline \multirow{7}{*}{$\begin{array}{c}\text { Collaborative } \\
\text { innovation } \\
\text { environment } \\
\text { construction capacity } \\
\text { (W3) }\end{array}$} & C19 Management system and regulations \\
\hline & C20 Capital investment \\
\hline & $\begin{array}{l}\text { C21 Participation of enterprises, intermediaries, } \\
\text { government and other innovation subjects }\end{array}$ \\
\hline & C22 Collaborative innovation unit quantity and scale \\
\hline & C23 Information construction site construction \\
\hline & $\begin{array}{l}\text { C24 Strategic objectives development and } \\
\text { development plan }\end{array}$ \\
\hline & $\begin{array}{l}\text { C25 Scientific rationality, open and transparent } \\
\text { budget }\end{array}$ \\
\hline
\end{tabular}

IV. SYSTEM CONSTRUCTION AND APPLICATION OF ENTROPY FUZZY MATTER ELEMENT EVALUATION MODEL

\section{A. Model building}

The entropy method is used to determine the weighting coefficient, and Euclid approach degree is used to evaluate the synergistic ability of each center. The concrete steps are as follows:

1) Construction of complex fuzzy matter element $n$-dimensional matter-elements of $m$ objects are combined as the $n$-dimensional complex fuzzy matter-element of evaluation $R m n$ indexes.

$$
R m n=\left[\begin{array}{ccccc} 
& M 1 & M 2 & \ldots & M m \\
C 1 & X 11 & X 12 & \ldots & X 1 m \\
C 2 & X 21 & X 22 & \ldots & X 2 m \\
\vdots & \vdots & \vdots & \vdots & \vdots \\
C n & C n 1 & C n 2 & \ldots & C n m
\end{array}\right]
$$


2) Complex fuzzy matter-element from membership degree, standard and difference

According to the definition of membership degree, the following formula can be used. Maxxij and Minxij are the maximum and minimum values of index:

$$
\begin{aligned}
U_{i j} & =X_{i j} / \operatorname{Max}_{i j} \\
U_{i j} & =\operatorname{Min} X_{i j} / X_{i j}
\end{aligned}
$$

$U i j$ is the membership degree; when the selected evaluation index is $X i j$ positive (the larger, the better), the first formula is used for calculation; otherwise, the second formula is used; the fuzzy membership matter-element $R^{\prime} m n$ be built. According to the maximum or minimum value of each index in $R^{\prime} m n$, the standard fuzzy matter-element $R o M$ can be constructed. Finally, the squares of standard fuzzy matter element $R o M$ and compound fuzzy matter Rnm can be combined to be the difference square compound fuzzy matter.

3) Determination of evaluation index weight coefficient via entropy method

According to the definition of entropy, $n$ evaluation target entropy of $m$ evaluation objects is:

$$
H i=-\sum_{i=1}^{n} p i j \ln p i j / \ln m(i=1,2, \ldots, n ; j=1,2, \ldots m)
$$

among which $p i j=x i j / \sum_{j=1}^{m} x i j$;

Calculate the weight $W$ and entropy weight $W_{i}$ of evaluation index:

$$
\begin{aligned}
& W=(W i) 1 \times n \\
& W i=(1-H i) /\left(n-\sum_{i=1}^{n} H i\right) \text { meeting } \sum_{i=1}^{n} W i=1
\end{aligned}
$$

\section{4) Evaluation of Euclid approach degree}

Euclid approach degree indicates the approach degree of the sample to be evaluated and the standard sample. The larger the value is, the closer they will be, and the higher the synergy degree will be; otherwise, the lower the synergy degree will be :

$$
\begin{aligned}
& \rho P H=\left[\begin{array}{rrrrr} 
& M_{1} & M_{2} & \ldots & M m \\
P H_{j} & P H_{1} & P_{2} & \ldots & P H_{m}
\end{array}\right] \\
& \text { among which }{ }_{P H_{j}}=1-\sqrt{\sum_{i=1}^{n} W_{i} \Delta_{i j}}(j=1,2, \ldots m)
\end{aligned}
$$

\section{B. Case application}

According to the "Statistical Yearbook of Science and Technology in Hubei Province" and the summarized data, this study selected 12 collaborative innovation centers from 56 collaborative innovation centers in 2015, and each grade is assigned as 5,4,3,2,1 point. According to expert scoring and processing, the complex fuzzy matter element is established. According to Step 1, difference square fuzzy matter element is calculated via the standard fuzzy matter element.

According to Step 3and 2, the entropy $\mathrm{Hi}$ and weight Wi of $c 1 \sim c 25$ are calculated as follows:

$H i=(0.980897349, \quad 0.943591178, \quad 0.981981619$, $0.948627268,0.965710989,0.972757971,0.970922832$, 0.945930889, 0.977639343, 0.972098013, 0.980897349, 0.981461466, $0.941781465,0.983602502,0.982858507$, $0.982708625,0.983281773,0.968857776,0.962313443$, 0.980204972, 0.978290441, 0.984224462, 0.988397229, 0.978639654, 0.978581894)

$W i=(0.02794,0.08250,0.02635,0.07513,0.05015$, $0.039840 .04253,0.07908,0.03270,0.04081,0.02794$, $0.02711,0.08515,0.02398,0.02507,0.02529,0.02445$, $0.04555,0.05512,0.02895,0.03175,0.02307,0.01697$, $0.03124,0.03132$ )

Euclid approach degree is calculated, and the approach degree $\rho P H$ can be obtained according to Step 5:

$$
\rho P H=\left[\begin{array}{ccccccc} 
& T 1 & T 2 & T 3 & T 4 & T 5 & T 6 \\
P H i & 0.8572 & 0.8562 & 0.7764 & 0.6724 & 0.7114 & 0.6625 \\
& T 7 & T 8 & T 9 & T 10 & T 11 & T 12 \\
& 0.5724 & 0.5340 & 0.5415 & 0.3689 & 0.3324 & 0.3500
\end{array}\right]
$$

\section{Result analysis}

1) From the results of Euclid approach degree, it can be seen that the collaborative innovation ability of Hubei collaborative innovation center from high to low is: T1, T2, T3, T5, T4, T6, T7, T9, T8, T10, T12 and T11 (the code indicates the center due to the confidentiality of data). The comparison of results of the empirical test and the performance ranking of Hubei collaborative innovation center in 2015 showed that this empirical study is in agreement with the results of assessment, proving that the empirical model used in this paper can reflect the actual situation.

2) According to the weight distribution of 25 evaluation indexes, the top ten indexes are C2, C4, C5, C6, C7, C8, C10, C13, C18 and C19, namely the research personnel investment, number of high-level papers and books published, provincial and ministerial scientific achievements awards, patent rights and software products, solve the key technical problems of industry, provide decision support for local government, talent introduction and training, the number of innovative academic meeting, innovative risk sharing and prevention mechanisms, management systems and regulations.

3) T1 and T2 have higher overall collaborative innovation ability, followed by T3, T4, T5, T6, T7, T8 and T9, and T10, T11 and T12 rank last. T1 and T2, as the two centers of colleges and universities, are characterized by scientific research investment, personnel investment and platform construction. At the same time, they focus on the internal exchange in the production and research collaboration with good risk-sharing mechanism, outstanding integration capacity 
and high conversion rate. The development of center also has good system guarantee and forward-looking planning.

\section{CONCLUSION AND POlicy SUgGestion}

The synergistic innovation ability of university collaborative center needs to be promoted from three aspects: input-output, main subject and environment construction, so as to integrate the multi-resources, realize the maximum output from knowledge to technology and from technology to economy. So we make the following recommendations:

1) Optimize and improve the investment structure and efficiently use the innovative resources. The innovative element input will greatly affect the innovation output, and only by rational allocation and application of innovative elements can maximize the innovation output and enhance the collaborative innovation ability. Therefore, the government should take everything into account in the allocation of resources, and focus on the new collaborative innovation center from the financial policy, and avoid excessive concentration of resources. At the same time, the center should cooperate with local enterprises and financial intermediaries to fully integrate resources and develop their own characteristics.

2)Broaden investment and financing channels, and strengthen the innovation talent and team management. Optimize the collaborative financing environment, and solve the shortage of funds of center in the talent introduction through a variety of channels, including loans and allowances, financial sharing plan and special funds for talent introduction, welfare allowances to attract and retain talents, and support the high-level innovative talent introduction, improvement of scientific research conditions, first-class disciplines and firstclass school platform construction, etc. At the same time, establish the good personnel recruitment and assessment mechanism in the institutional mechanism to attract and retain the talent team.

3) Support diversified cooperation, promote the in-depth collaboration of main subjects. The center should further promote the integration among collaborative innovation subjects, boost enterprise technological innovation and transformation and promote scientific and technological work in universities, so as to better serve the local economic construction. Build the cross-field and cross-regional synergy alliance, and gather the innovation power to achieve the optimal allocation of innovative elements and the optimal integration of resources and enhance the scientific research and technological innovation ability in the service of social development.

4) Improve the management system, and create a good environment for collaborative innovation. The collaborative innovation centers should adhere to the personnel operation mechanism of "open, mobile, competitive and shared", build the flexible talent system and implement the open system, sharing system and mobile system with competition and selection as the principle, so as to realize the staff gathering and withdrawal. In terms of liability distribution, focus on organizational strategy and multi-unit building is not recommended, in order to avoid the unclear entity responsibility.

\section{REFERENCES}

[1] Lan Xiaoxia, Research on Cooperative Innovation Mechanism of American Industry University Research, Beijing: Beijing Jiaotong University Press,PP. 273,2014.(In Chinese)

[2] Barton R.Developing innovative competences: The role of institutional frameworks. Industrial and Corporate Change,2002,11( 3) ,PP.497528.

[3] Simatupang T M, Sridharan R. The collaboration index: A measure for supply chain collaboration. International Journal of Physical Distribution \& Logistics Man-agement,2005,35( 1),PP.44 -62.

[4] Larry J,Santamara L. The importance of diverse collaborative networks for the novelty of product innovation.Technovation,2007,27( 67) ,PP.367-377.

[5] Barbaroux P. identifying collaborative innovation capabilities within knowledge-intensive environments: Insights from the A R PANET project.European Journal of Innovation Management,2012,15( 2) ,PP. 232-258.

[6] Xie Xuemei, Zeng Saixing, Evaluation of Sustainable Innovation Ability System of Science and Technology Industry Cluster, Journal of Systems Management, 2008, 17 (3),PP.241-247. (In Chinese)

[7] Ou Guangjun, Liu Siyun, Jiang Huanyun, Evaluation and Empirical Study on Synergistic Innovation Ability of High-tech Zone from Perspective of Industrial Clusters , Science and Technology Progress and Countermeasures, 2013,30 (7),PP.123-129. (In Chinese)

[8] Kang Jian, Research on Evaluation of Triple Helix Collaborative Innovation Ability Based on Regional Industry Interaction, Journal of Scientific Research, 2014,35 (5),PP.19-26. (In Chinese)

[9] Wen Ke, Su Hongyu, Zhou Huadong, A Study on the Cooperative Innovation Ability of Scientific Research Institutions: An Empirical Analysis Based on 101 Public Research Institutes in China, Studies in Science of Science, 2014,32 (7),PP.1081-1089. (In Chinese)

[10] Wang Wengjuan, Wei Huaian, Construction of Cooperative Innovation Ability Evaluation Index System: Empirical Research Based on National Key Laboratory, Studies in Science of Science, 2016, 3 (34),PP.471-480. (In Chinese)

[11] Fu Yifan, An Empirical Study on Mechanism of Industry University Institute Cooperative Innovation in Henan Province, Economic Research Guide, 2014 (18),PP. 47-48.(In Chinese)

[12] Ding Hong, Research on Collaborative Innovation Ability Evaluation of Scientific Research Team in Universities, Chinese Science Research of University, 2013(11), PP.41-43. (In Chinese)

[13] Wang Jiefang, Research on Performance Evaluation System of Collaborative Innovation Center, Chinese Science Research of University, 2014 (4), PP.59-61. (In Chinese)

[14] Li Yongzhou, Huang Zhenzhen, Research on Talent Network Embedding and Performance Evaluation of Collaborative Innovation Center of Universities, China Science and Technology Forum, 2015 (10), PP.142-148. (In Chinese) 